\title{
The Role of Public Policy in Enhancing the Design and Diffusion of Information Systems and Technology for Human Benefit
}

\author{
John Venable ${ }^{1}$, Peter Newman ${ }^{2}$, Nick Letch $^{3}$, and Sue Ash ${ }^{4}$ \\ ${ }^{1}$ Curtin University of Technology, \\ Perth, Western Australia \\ ${ }^{2}$ Curtin University Sustainability Policy Institute, \\ Perth, Western Australia \\ ${ }^{3}$ University of Western Australia, \\ Perth, Western Australia \\ ${ }^{4}$ Western Australian Council of Social Service Inc., \\ West Perth, Western Australia
}

Technologies for human benefit, such as information systems and information technology, have a key role to play in the realization of quality of life for all citizenry by modern societies. New forms of IS and IT can be developed and used creatively to improve education, health, social equity, environmental conditions, social and environmental sustainability, government and not-for-profit services, participation in government, and enjoyment of life in general.

However, potentially valuable new technologies for human benefit may not be utilized due to barriers inherent in capitalist economies, including barriers to design and development of new technologies and barriers to adoption and diffusion of those new technologies. Some barriers to development stem from the profit motive, including lack of funding where sufficient return (profit) is not expected (or not returned soon enough), competitive forces leading to incompatibilities between different technologies (e.g., through product differentiation and creation of barriers to entry), and potential competition of new technologies for human benefit with established profit-making technologies. Barriers to adoption and diffusion of new technologies for human benefit include the expense and risk of new, possibly untried technologies, issues of organizational and social change, and lack of understanding of the role, purpose, potential benefits, and ways to obtain and use newly developed technologies.

Public policy has a key role to play in the development of new and adoption of new or existing technologies for human benefit. Governments and other policy development organizations may propose and implement public policy that provides funding or other incentives for development and adoption of technologies. Public policy may be used to set key priorities or technical directions or establish appropriate shared infrastructure. Public policy may regulate (or deregulate) how businesses or other organizations develop, deploy, or compete for and use new technologies to achieve improved human benefit. 
This panel will examine the role of public policy in encouraging the design, development, and adoption of new technologies, particularly information systems and technologies that have the goal of providing benefit to members of the public and humanity in general. Key areas and priorities for needed or changed public policy will be identified, together with recommendations for useful changes to public policy and how researchers may best engage in influencing public policy for human benefit. 